\title{
The burglar as a space explorer in his own neighborhood
}

\author{
A. van Nes \\ Section of Urban Renewal and Management, Faculty of Architecture, \\ Delft University of Technology, The Netherlands
}

\begin{abstract}
An area's social and spatial composition influences burglary rates in built-up environments. A more adequate understanding of the relationship between an area's social and spatial composition requires data about burglars' home addresses and about the homes they intruded. For consideration, exemplary investigation data of 39 burglars caught operating in the Dutch town of Haarlem were obtained from the regional authorities. In 32 of the 39 cases the burglar lived within a radius of $3 \mathrm{~km}$ away from the homes they burgled. In most cases, the burglars operated in those areas in their neighbourhood that were spatially most segregated and that had the most broken up street network. As this initial investigation suggests, burglars have a detailed practical knowledge of the areas in which they operate. Apparently, their know-how results not just from information about their victims and their neighbours' presence, but also from information on comprehensive spatial conditions. The more burglars living in an area, the higher the burglary rates. However, the burglaries take place in the spatially most segregated and unconstituted part of the burglars' own neighbourhood.

Keywords: spatial configuration, burglars home addresses and their break-ins, urban segregation.
\end{abstract}

\section{Conditions for break ins}

Being able to burgle a home, a burglar must somehow break into it unnoticed by neighbours or passers by. Similarly, the burglar must leave the home with the stolen items unseen. He needs alternative escape routes in case he meets someone on his way. Moreover, he must hide away the stolen items as soon as possible at a safe 
place. In this context burglars have to know the area where they operate in very well. In most cases it seems to be in the neighbourhood where they live [1, p. 237, 237, 337-344] and [2, p. 423-435].

Before burglars act, presumably careful planning and registration are done in advance. They register to what extent inhabitants or their neighbours are present, whether they have dogs, the quality of security locks and alarms, the degree of cover from bushes and fences, and the location of the best invisible points of entry $[3$, p. 2]. A planning of this kind implies frequent walks through an area in order to explore all the spatial possibilities with reference to the temporal conditions it offers.

Few people in the streets and few people at home in an area seems to be preferred by burglars. Dwelling areas with few people in streets indicate an easy identification of strangers. All above-mentioned aspects taken into account, it is likely that the burglar must be among an area's inhabitants. Burglars are space explorers driven to gain marketable goods. For this purpose, they depend on an area's manifold conditions.

In an interview of caught burglars, Bennett and Wright conclude that burglars are obviously concerned with two main risk issues: Degree of visibility and occupancy of the dwelling [3, p. 85]. The first aspect depends on the area's spatial composition while the second one requires local knowledge about the degree of presence of an area's inhabitants.

If a burglar must be invisible, what kind of areas does he prefer? From a burglar's perspective, traditional urban areas favour his criminal interest by the way he can mingle with the passers by frequenting these areas. He can carry out his careful planning and registration unnoticed by the inhabitants $[4$, p. 51]. A feature of traditional urban areas is a distributed street structure with a complex network of movement routes, which allow for several escape route possibilities. However, the frequently high number of people in the streets might cause an obstacle.

Post War areas are frequented less and nevertheless offer many escape routes. The street structure is mostly non-distributed as regards the car traffic routes in dwelling areas, while it is distributed on the main routes between the dwelling areas. Inside the dwelling areas the escape routes are many where there exist a network of footpaths. The number of people frequenting these areas is low. However, in these contexts the burglar is easily recognised as a stranger. In order to be successful in these kinds of areas, he must then likely to be one of the inhabitants. Hence the question as to whether a burglar is himself a local inhabitant affects the issue under concern.

\section{Earlier research on space and crime}

Empirical research on crime and space is marked by the controversy between Jacobs' conception of lively, permeable urban environments and Newman's conception of closed, defensible space. For extended reports on this debate cf. Hillier and Shu [5], Newman [6, 7] Jacobs [8]. In Jacobs' view passers-by, i.e. strangers as well as inhabitants, function as a natural form of surveillance. In 
Newman's opinion just strangers count as possible intruders. The inhabitants' behaviour, and the look and structure of their dwellings are taken to be effective means of defence against them.

In general research with space syntax method shows in what ways segregated streets have more complex routes to all other streets in a city. Empirical research with a configurative approach shows that areas with segregated spaces, with urban grids visually broken up and with few dwelling entrances constituting streets are often affected by crime and social misuse [5, p. 232]. The same investigations prove that spatial organisation can generate movement according to co-presence and co-awareness in a built environment [9, p. 29-66].

In her article Crime and space in the inner city, Valerie Alford identified the spatial features of different types of crime. Her main conclusions are that different types of street crime takes place in different kinds of space and that crime and pedestrian flow are clearly linked [10, p. 64-67].

In his PhD thesis Housing Layout and Crime Vulnerability, Chih-Feng Shu investigated the correlation between the spatial configurative layout of housing estates and urban areas with the spatial distribution of property offences. Three different areas were investigated over a two years period. His findings provide evidence against the defensible space and territoriality ideas. Property crime tends to take place in segregated urban areas, especially in cul-de-sacs or enclosed clusters favoured by Oscar Newman [11, p. 2, 444-446].

Shu's research differs from earlier research in that he provides detailed spatial studies on dwelling areas with a wide range of different types of dwellings, streets, or of spatial and social composition. Causes for social misuse of a given area can be understood from an intrinsic or topological spatial point of view. It depends on at least the following conditions: Bad correlation between street connectivity and spatial integration of the vicinity, the segregated areas are many topological steps away from integrated streets, and the topological spatial structure of the area is deep, in itself and as regards both the whole system. Likewise enclosed spatially systems with high privacy, but without general social control lack natural co-presence and mutual surveillance [12, p. 188, 194, 201]. These conclusions are so far based on a few cases studied in the UK.

In research on crime in built environments one has to be aware of the fact that spatial factors can be overrun by social ones. In this respect research from criminologists has to be taken into account. According to the routine activity theory promoted by Felson and Cohen [13, p. 389-405] as well as the crime pattern theory promoted by Brantingham and Brantingham [4] criminals operate in the areas where they live, recreate and work. The spaces along their daily movement routes are named awareness space. Inside the awareness space opportunity spaces are located. The present inquiry identifies the spatial configurative features of the opportunity spaces with the help of space syntax method. The results from the Haarlem study show that the opportunity spaces are the most segregated and unconstituted streets within a radius of $3 \mathrm{~km}$ from a burglar's home address. 


\section{The study of Haarlem}

In an ongoing research project for the Dutch police, the criminologist Manuel Lopez is developing and testing out a method in order to localise where burglars live based on the location of burgled homes. He provides data of 39 caught burglars in Haarlem. In $80 \%$ of the cases the burglar lives and lived within a radius of $3 \mathrm{~km}$ from the homes they burgled. Lopez drew a radius of $3 \mathrm{~km}$ around the burgled homes. In most cases the home of the burglar was in the area covered by the largest overlap of the circles [2, p. 423-435]. The analysis could be compared with spatial configurative analyses of Haarlem. The latter were carried out with the purpose of identifying the spatial features of streets where burglars operate in their vicinity.

Apparently, burglars tend to prefer housing layouts designed in accordance with Newman's assumptions. These results tacitly favour Jacobs' position. The present study scrutinises this stance by considering the previous and past home addresses of caught burglars. Burglaries are reported in all detail at police offices as regards point of entry into private space and escape routes back into public space. Moreover, Lopez' study on burglars' home address and of the area which they operate can provide more precise evidence on the correlation between spatial configuration and social composition than previous ones.

The space syntax method consists in calculating the degree of a street's integration in relation to all other streets in a built environment. In order to visualise the degree of integration colour codes are used in order to represent the various integration values of the streets. The black lines show the $10 \%$ most integrated streets, while the light grey lines are the most segregated ones. A global integration analysis shows how each street relates topologically to all other streets in a whole city, while a local integration analysis shows how centrally a street is located in comparison to other streets in its direct vicinity. Research has shown that streets with high integration have high number of pedestrians while the number is low in streets with low integration [9, p. 31].

Another way to study the topological depth of an area in relation to the whole city consists in marking the main routes through a city. They can be identified from a tourist map over a city and its region. In the Guide Michelin, for example, these routes are highlighted in order to inform strangers for way finding through a city. Inhabitants use these roads regularly. Stephen Read uses the concept middle scale network for these main routes [14, p. 343]. In historic city centres the middle scale network goes through different urban areas, while in post war areas it goes between urban areas. If one marks the middle scale network in black, all the streets directly connected to the middle scale network in grey and the remaining streets in light grey, the results indicate the topological depth of a city's various areas. If one has to change directions many times from a middle scale network into an area, the area is topological deep. If one has to change directions few times, the area is topological shallow. As this study shows, burgled homes are located in topologically deep areas - thus along the light grey coloured streets. 
These results indicate where burglaries occur in built environments. However, micro spatial measurements like the degree of inter-visibility of entrances seem to influence a street's burglary rate.

In this study four different degrees of entrances' inter-visibility were used. A street is highly inter-visible if the density of entrances is high and more than $75 \%$ of them are inter-visible to one another. An inter-visible street has a low density of entrances, but more than $75 \%$ must be inter-visible for one another. A street has little inter-visibility if and only if the density of entrances is high and more than $75 \%$ of them are located on one side of the street. A non-visible street has low density of entrances and less than $75 \%$ of them are inter-visible for one another. Likewise, streets with no entrances at all or in which the entrances are covered by high hedges and fences are defined as non-visible.

In order to review the role of entrances' degree of inter-visibility, studies of four criminals have been done in detail. The following spatial properties will be discussed: Global and local integration, depth from the middle scale network and the entrances' degree of inter-visibility.

Figure 1 shows the dispersal of burglaries and of previous or old home addresses of the criminal named Jan. As can be seen in the figure, Jan chooses the most segregated areas within a radius of $1.5 \mathrm{~km}$ from one of his homes. Most of his burglaries are concentrated in a dwelling area where urban renewal took place in the 1980's. The streets in this area are not only spatially segregated and broken up, but they also have a low degree of inter-visible entrances. The area itself is topological deep of the middle scale network, and the entrances of the intruded homes are inter-faced with high fences and hedges from back gardens.

Presenting another criminal, named Piet, figure 2 shows the dispersal of burglaries in a quite different area. The affected streets are not as segregated as in figure 1. However, a feature of the streets where Piet relate to the way some entrances are covered by high hedges, these houses have a rear access through the back gardens. About 500 meter north of these streets, lies a working class area where the streets are inter-visible and constituted by a high density of entrances. All streets have high local and global integration. Moreover, the area is topologically shallow from Haarlem's middle scale network. The blocks are clearly defined and the entrances are directly connected to the street. There are no rear accesses to the dwellings. In the study of all the 39 burglars almost no burglaries are registered in this area - even though one of the burglar's home address is located inside it.

The criminal Jack lives in a modern Dutch Post War dwelling area with separate pedestrian and vehicle street nets. As figure 3 shows, the whole area is segregated and topologically deep as regards the middle scale network, entrances are not intervisible to one another, and the density of entrances constituting streets is low. The car traffic routes are non-distributed, while the pedestrian routes are distributed and unconstituted.

Jack's break ins are located in the low-rise dwelling areas with rear access to back gardens. Due to their concealed indirect entrances the high rise flats are not 

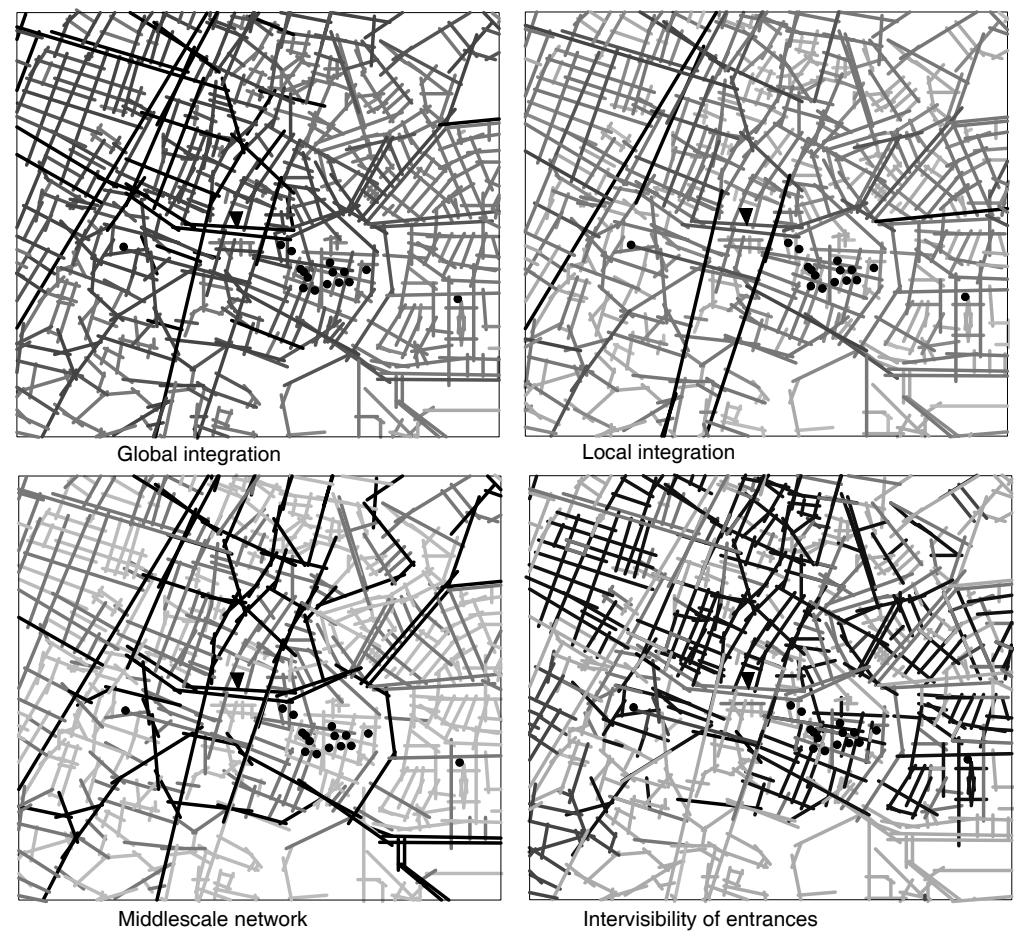

The burglar's homeadresses
- The burglar's burglered homes

— High intervisible street, high density of entrances

- Intervisible street, low density of entrances

- Low intervisible street, high density of entrances

- Non intervisible street, low density of entrances

Figure 1: Criminal Jan (Global, local, Middle-scale, inter-visibility).

affected at all. The whole area offers several escape routes through a network of unconstituted footpaths and bicycle routes.

The criminal Bas operates in a pre-war suburbia traditional dwelling area consisting of typical Dutch working class row houses mostly built in the 19201930 's and of some high rise flats. His preferences are houses located topologically deep of the middle scale network, houses located in locally segregated streets, and in corner houses. The corner houses offer more escape routes and have less visible neighbours than other houses in the area. As illustrated in figure 4 the area itself has a low global integration, but the street net is distributed.

As this detailed study of four burglars shows, they presumingly prefer to operate in streets with low inter-visibility of entrances, low local and global integration, and in streets located topologically deep from the middle scale network. Furthermore, dwellings with rear access to back gardens or where the entrances are covered by high fences or hedges are preferred. 


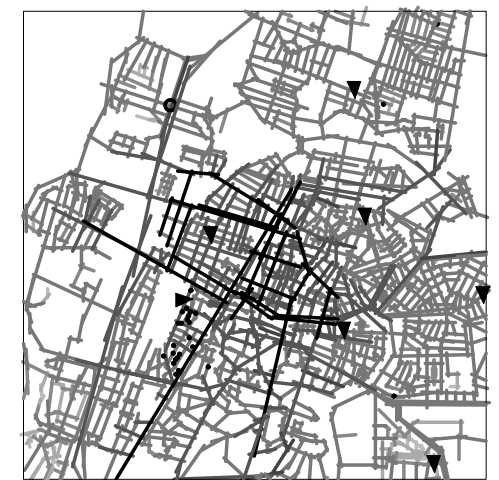

Global integration

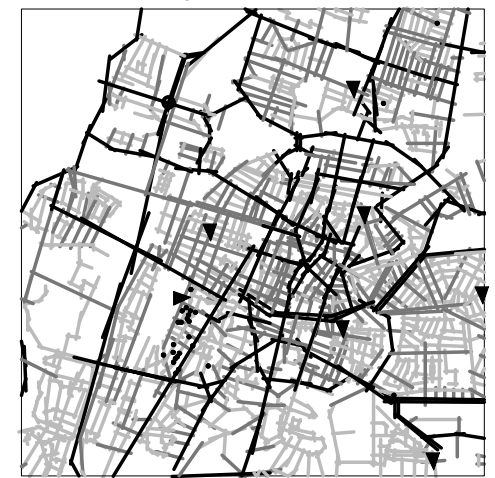

Middlescale network

The burglar's homeadresses

- The burglar's burglered homes

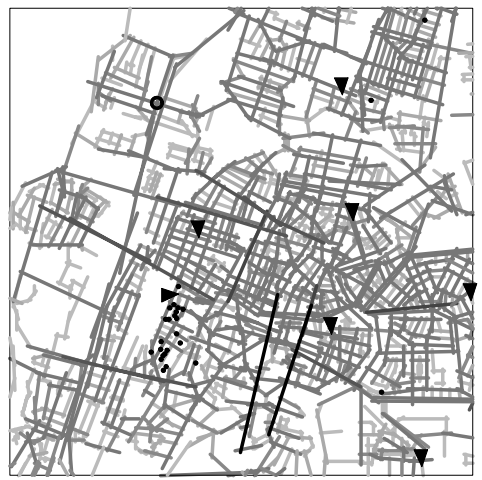

Local integration

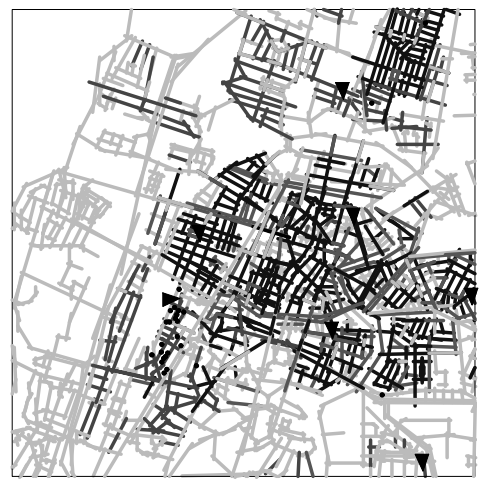

Intervisibility of entrances

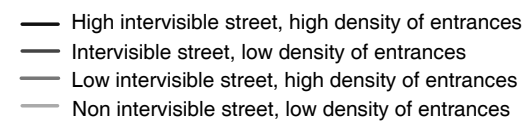

Figure 2: Criminal Piet (Global, local, Middle-scale, inter-visibility).

\section{Conclusions as regards Haarlem}

In the first instance burglars have a certain kind of local knowledge of the areas they operate in. It seems not only to depend on knowledge about when people are not present at their homes, but also in knowledge on the spatial conditions on where these homes are located. Essential are the very local spatial conditions of break in points and escape routes.

Secondly, burglaries seem to occur in the most segregated and topologically deepest section within a radius of about $3 \mathrm{~km}$ from the burglar's home. They seek for the most segregated streets with the greatest potential of escape routes and the lowest degree of inter-visibility with neighbours. The spatially weakest points in a burglar's neighbourhood are affected most. In most cases it occurs in segregated streets with little inter-visibility. 

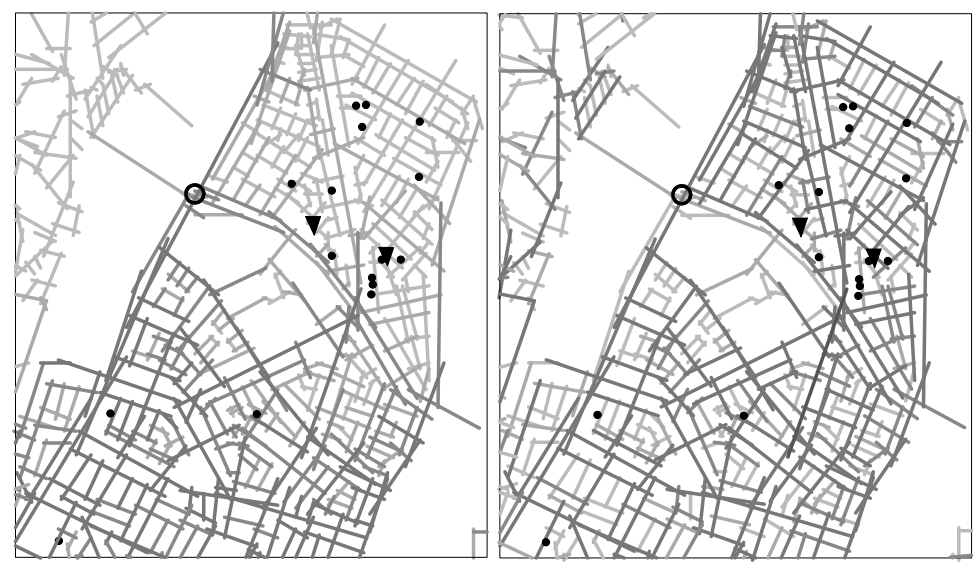

Global integration

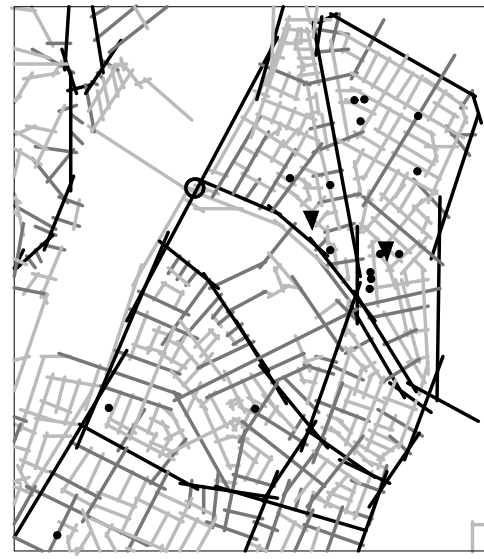

Middlescale network

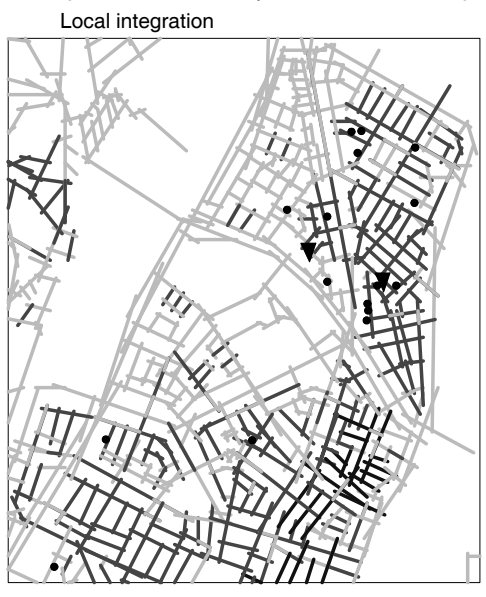

Intervisibility of entrances

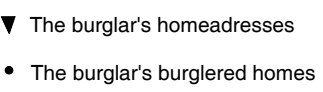

- High intervisible street, high density of entrances
Intervisible street, low density of entrances
Low intervisible street, high density of entrances

Figure 3: Criminal Jack (Global, local, Middle-scale, inter-visibility).

Thirdly, not the density of entrances but inter-visibility is significant. Burglars favour invisible break in points invisible on account of high fences and hedges or of few neighbours across the street. As regards escape possibilities, unconstituted footpaths and segregated streets are preferred. The same pertains to spatially broken up street structures with no natural surveillance.

The conclusions above are only based on caught criminals. One could ask what the result would be if unsolved cases could be taken into account. Do professional burglars operate within a large radius from their home address? Or do they cooperate with less professional criminals who know their own neighbourhood very 

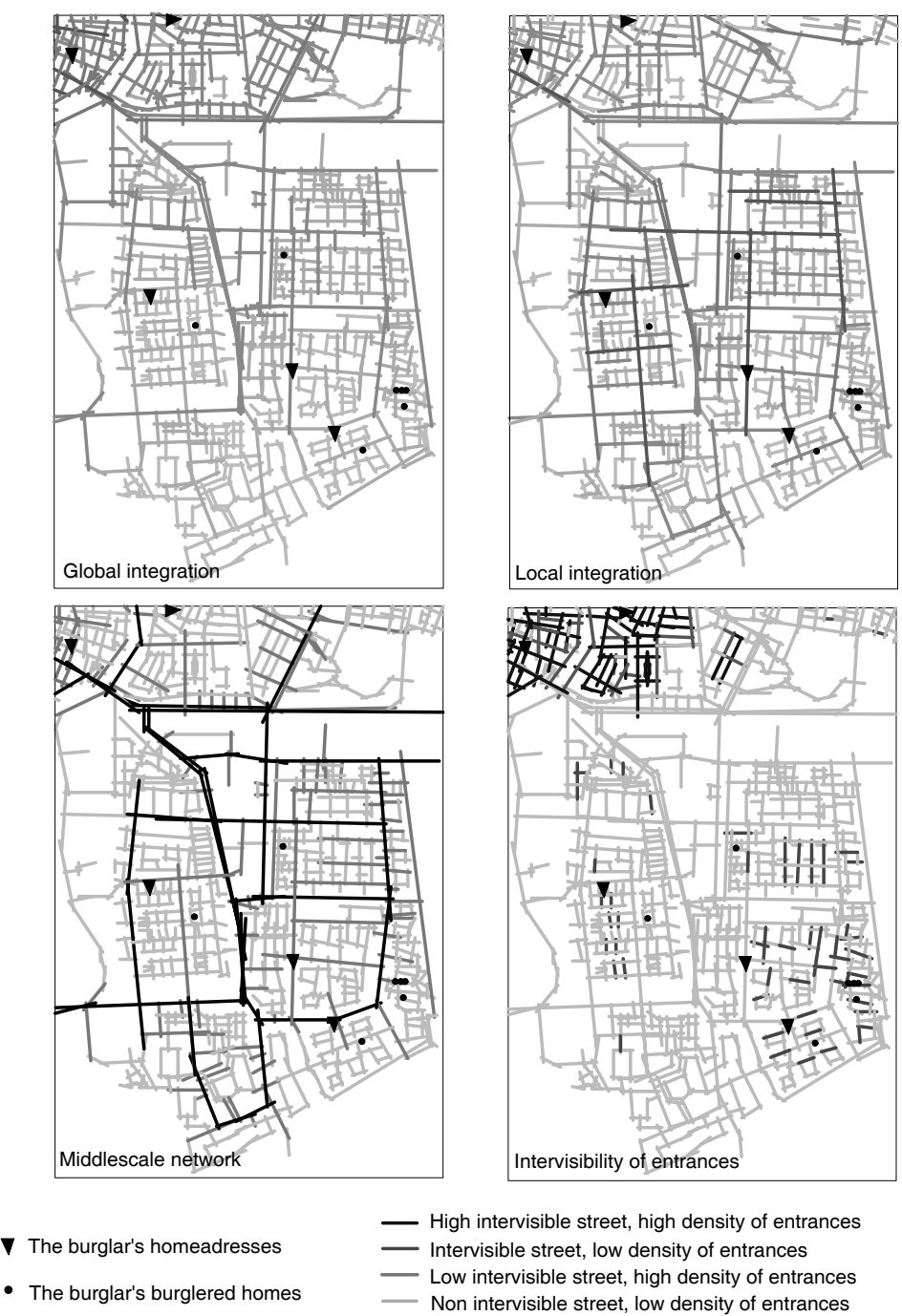

Figure 4: Criminal Bas (Global, local, Middle-scale, inter-visibility).

well? Or are their professional skills at such a high level that the spatial conditions do not play a role at all?

Analyses of known criminals, combined with a space syntax analysis allow for an understanding on criminals' choice preferences in relationship to their own homes in built environments. Furthermore, an analysis of this sort allows to gain knowledge about how an area's social composition in correlation with spatial composition affects the dispersal of burglaries. The study of Haarlem based on information provided by the Dutch police roughly confirms Shu's work, but 
seemingly indicates that one should account for the chance that one's neighbour is a burglar.

\section{References}

[1] Brantingham, P. \& Brantingham, P., Patterns in Crime. Macmillan Publishing Company: New York, 1984.

[2] Lopez, M., The spatial behaviour of residential burglars. Proceedings 5th International Space Syntax Symposium, ed. A. van Nes, Techne Press: Delft, pp. 423-435, 2005.

[3] Bennett \& Wright, Burglars on Burglary. Prevention and the offender. Gower Publishing Company Limited: Aldershot, 1984.

[4] Brantingham, P. \& Brantingham, P., Environmental Criminology. Sage Publications: Bevery Hills, Aldershot, 1981.

[5] Hillier, B. \& Shu, S., Crime and urban layout: the need for evidence. Secure Foundations. Key issues in crime prevention, crime reduction and community safety, eds. K.P. S. Ballintyne \& V. McLaren, Institute for Public Policy research: London, 2000.

[6] Newman, O., (ed.) Defensible Space. Crime prevention through urban design. Macmillan Company: New York, 1972.

[7] Newman, O., (ed.) Community of interest. Anchor Press: Doubleday, New York, 1980.

[8] Jacobs, J., (ed.) The Death and Life of Great American Cities. Pimlico: London, 2000.

[9] Hillier, B., Penn, A., Hanson, J. et al., Natural movement: or, configuration and attraction in urban pedestrian movement. Environment and Planning B: Planning and Design, 20, pp. 29-66, 1996.

[10] Alford, W., Crime and space in the inner city. Urban Design Studies, pp. 4576, 1996.

[11] Shu, C.F., Housing Layout and crime vulnerability. $\mathrm{PhD}$ thesis, Bartlett School of Graduate Studies, University College London: London, 1984.

[12] Hillier, B., Space is the Machine. Cambridge University Press: Cambridge, 1996.

[13] Felson, M. \& Cohen, L.E., Human ecology and crime: a routine activity approach. Human Ecology, 8(4), pp. 389-405, 1999.

[14] Read, S., Flat city; a space syntax derived urban movement network model. Proceedings 5th International Space Syntax Symposium, ed. A. van Nes, Techne Press: Delft, pp. 341-357, 2005. 